TPPeriodica Polytechnica

Social and Management Sciences

22(2), pp. 75-85, 2014

DOI:10.3311/PPso. 7259

Creative Commons Attribution (1)

RESEARCH ARTICLE

\section{Flow-based Capacity Allocation in the CEE Electricity Market: Sensitivity Analysis, Multiple Optima, Total Revenue}

\author{
Ákos Füzi / Gergely Mádi-Nagy
}

RECEIVED 13 January 2014; ACCEPTEd AFter REVISION 6 FEBruary 2014

\section{Abstract}

The paper introduces the mechanism of the Flow-based Capacity Allocation (FBA) method on the electricity market of the Central-Eastern Europe (CEE) Region, proposed by the Central Allocation Office (CAO). The method is a coordinated heterogeneous multi-unit uniform price auction where the allocation is determined by the solution of a linear programming problem. On one hand, the properties of the underlying linear programming problem are discussed: the possibilities of multiple solutions are analysed, then a non-standard sensitivity analysis method of the market spread auction is developed. On the other hand, a global optimization problem is presented that yields uniform auction prices corresponding to higher total income than at the original allocation method. Several numerical examples and results of practical test problems are presented.

\section{Keywords}

Linear programming $\cdot$ Sensitivity analysis $\cdot$ Auctions $\cdot$ Global optimization · Electricity Market

\footnotetext{
Ákos Füzi

IP Systems Ltd.

e-mail: akos.fuzi@ipsystems.hu

Gergely Mádi-Nagy

Eötvös University and IP Systems Ltd.

e-mail: gergely@cs.elte.hu
}

\section{Introduction}

In the electricity market, beside the power exchange, transmission capacities are also traded. Transmission capacities mean the right to transmit a certain value of power in a given time period from a given source to a given sink of the electricity network. The original owners of capacities are the Transmission System Operators (TSOs). They can sell them to the users of the network (whole sale traders, retailers etc). There are several ways of capacity allocation: bilateral contracts, OTC markets, auctions etc.

In the following, a coordinated auction model is analysed, which is intended to be introduced to the CEE electricity market: the Central-Eastern Europe (CEE) region consists of Austria, the Czech Republic, Germany, Hungary, Poland, Slovakia and Slovenia. Only the so-called cross-border transmission capacities are considered, those are transmission rights between the areas of two different TSOs. Remark that, in the CEE, an area of a TSO (or association of TSOs) typically means an area of a country (countries).

According to the European Community Regulations 1228/2003/EC and 714/2009/EC, a market-based mechanism has to be adopted to allocate the capacities. It has the following requirements:

- prevention of overloading,

- efficient deals with interdependent physical flows,

- avoidance of discrimination in allocating electricity transmission capacities.

Hence, instead of the former OTC bilateral contracts, CEE TSOs intend to introduce stepwise a coordinated flow-based allocation of cross-border electricity transmission capacities at interconnections between CEE TSOs. The steps are

(a) Coordinated Net Transfer Capacity (NTC) assessment method. It is an explicit coordinated auction, however, only the available cross-border capacities are taken into account. This model is applied now.

(b) Coordinated flow-based allocation (FBA) method. It is planned to be introduced soon. This model takes the properties of the whole electricity network into account. 
There is a wide range of literature on congestion management methods as well as on their proposals for the European market. Regulation 1228/2003 is analysed by Boucher and Smeers (2002) and Ehrenmann and Smeers (2005). The investigated FBA method is based on zonal pricing: the properties of nodal, uniform or zonal pricing are discussed in Ding and Fuller (2005). Within the sectors uniform pricing is applied, however, e.g., the model of nodal pricing can be found in Stigler, Heinz, Todem and Christian (2005) (as regards Austria) and in Leuthold, Weigt and von Hirschhausen (2008) (as regards Germany). The publications, proposals of ETSO-E (2012) should also be taken into account.

The approach of our paper is different to the above. While most literature analysed the methods theoretically, our discussion is based on practice:

- instead of theoretical systems, the auction rules published by CAO (2011) are analysed and

- the FBA model has also been implemented and used in energy-trading Informatics Platforms of Systems Ltd.

On one hand, we would like to share the experiences of the implementation and tests of the method: focusing on multiple optima and sensitivity analysis. On the other hand, we would like to demonstrate an alternative auction model, which also fulfills the requirement of the European Community Regulations $1228 / 2003 / \mathrm{EC}$ and $714 / 2009 / \mathrm{EC}$, however, the total income of the TSOs are greater than the FBA method.

The paper is organized as follows. In Section 2 the FBA method is introduced. In Section 3 the cases of multiple optima and a particular sensitivity analysis are discussed. In Section 4 a global optimization problemis introduced in order to maximize the total income of the TSOs. Here some comparisons with the results of original FBA auction are presented. Section 5 concludes the paper. Finally, all notations and abbreviations are explained in the Nomenclature at the end of the paper.

\section{Mechanism of the FBA method}

The coordinator of the auction is the Central Allocation Office (CAO), which is founded and owned by the TSOs of the $\mathrm{CEE}$ region. The detailed rules of the market can be found on the CAO website (CAO 2011). In order to make the paper self-contained, the auction rules are summarized in this section.

There are eight TSOs (APG, CEPS, ELES, TENNET, MAVIR, PSEO, SEPS, a.s. and 50HzT), however, in the market APG, TENNET and 50HzT constitute one zone. Hence, the trade is possible among five zones. Regarding the type of the auctions there are yearly, monthly and daily auctions. In case of daily auction, capacities can be purchased separately for each hour of the day.

As regards the scheduling of the auction: in the first period (called nomination) the market participants submit their bids (extended with a correction cycle), then in the second period the CAO calculates the auction prices, capacity allocations and announces them at a certain cut off time.

\section{Every bid consists of}

- the source-sink pair, i.e. from which zone to which zone the capacity is required,

- the required quantity of capacity (in $M W$ ),

- the offered bid price for one unit capacity (in $E U R / M W h$ ).

The network is represented in the following way. Initially, the critical lines of the network are identified. Then, on one hand, a loading plan on the network is published: i.e., how many $M W S$ are loaded on each critical line in case of transmission of one $M W$ from a given zone to another given zone. On the other hand, the maximum available capacities of each critical line are presented.

The loads are represented by the Power Transfer Distribution Factors (PTDF) matrix. It is a set of PTDFs expressing the influence of commercial exchanges between all source-sink pairs to all critical lines (so called outage combination). I.e.,

- the value of

$$
\text { PTDF }\left(\text { Zone }_{x}, \text { Zone }_{y}, \text { line }_{k}\right)
$$

represents how much capacity is used on line in case of transmission of $1 \mathrm{MW}$ from Zone to Zone $_{y}$.

- Each line has a direction. If the actual Source-Sink pair uses the line in this direction, then the PTDF is positive, in case of opposite direction it is negative.

- The actual PTDF is published on the CAO ePortal (2011).

The Available Maximum Flow (AMF) values give the maximum capacities of the lines. I.e.,

- $A M F^{+}\left(\right.$line $\left._{k}\right)$ is the maximum capacity in the direction of line ${ }_{k}$,

- $A M F^{-}\left(\right.$line $\left._{k}\right)$ is the maximum capacity in the opposite direction.

The reason of the two different capacities corresponding to the directions is that they are remaining capacities after longterm contracts and previous auctions.

The PTDF and AMF values are published as an Excel file by $\mathrm{CAO}$, prior to the auction. In case of daily auction the values of each hour are on separate sheets. One example is presented on Figure 1. The columns mean the following:

Critical Branch: a critical segment of the network Case: ' $n-0$ ' means the primary physical element, the ' $n-1$ '-type cases are the standby physical elements. The latters are used in case of any failure of the primary element. In the modeling view, each Critical Branch/Case pair means a separate line.

Source: the physical source of the element Sink: the physical sink of the element

The whole sheet has $5 \times 4=20$ PTDF columns corresponding to the Source-Sink Pairs (5 Zones), and it has about 1000 rows (Critical Branch/Case pairs). 


\begin{tabular}{|c|c|c|c|c|c|c|c|c|}
\hline \multicolumn{9}{|c|}{ Technical Parameters for Test 2 Daily Auction 7A-7B } \\
\hline \multicolumn{2}{|c|}{ Parameters (1008) } & \multirow[b]{2}{*}{ Source } & \multirow[b]{2}{*}{ Sink } & \multirow[b]{2}{*}{ TMF } & \multirow[b]{2}{*}{ AMF+ } & \multirow[b]{2}{*}{ AMF- } & \multirow[b]{2}{*}{ MAVIR->PSEC } & \multirow[b]{2}{*}{ MAVIR->ELES } \\
\hline Critical Branch & Case & & & & & & & \\
\hline LINE_00001 & $n-0$ & $\mathrm{APG}$ & $\mathrm{APG}$ & 305 & 373.9 & 166 & 0.0076 & -0.0313 \\
\hline LINE_00001 & n-1 LINE_00002 & $\mathrm{APG}$ & $\mathrm{APG}$ & 305 & 413.1 & 126.9 & 0.0104 & -0.0433 \\
\hline LINE_00001 & n-1 LINE_00003 & $\mathrm{APG}$ & $\mathrm{APG}$ & 305 & 413.2 & 126.8 & 0.0105 & -0.0433 \\
\hline LINE_00001 & n-1 LINE_00004 & $\mathrm{APG}$ & $\mathrm{APG}$ & 305 & 363.9 & 176 & 0.0058 & -0.0299 \\
\hline LINE_00001 & n-1 LINE_00005 & $\mathrm{APG}$ & $\mathrm{APG}$ & 305 & 357.4 & 182.5 & 0.0059 & -0.0273 \\
\hline LINE_00001 & n-1 LINE_00006 & $\mathrm{APG}$ & $\mathrm{APG}$ & 305 & 387.2 & 152.7 & 0.0108 & -0.0207 \\
\hline LINE_00007 & $n-0$ & $\mathrm{APG}$ & $\mathrm{APG}$ & 303 & 163.8 & 371.7 & -0.0076 & 0.0313 \\
\hline LINE_00007 & n-1 LINE_00002 & $\mathrm{APG}$ & $\mathrm{APG}$ & 303 & 124.7 & 410.8 & -0.0104 & 0.0433 \\
\hline LINE_00007 & n-1 LINE_00003 & $\mathrm{APG}$ & $\mathrm{APG}$ & 303 & 124.5 & 410.9 & -0.0105 & 0.0433 \\
\hline
\end{tabular}

Fig. 1. Upper left corner of the PTDF of one hour of Daily Auction published by CAO.

\subsection{The LP model of the allocation}

The allocation method should find the most efficient capacity allocation subject to properties and limits of the transmission network and all bids together.

The auction is modelled by a linear programming $(L P)$ problem, detailed below, where the constraints describe the properties of the network. The objective function is the so-called social welfare function. It represents the efficiency of network usage measured by the financial value of allocated capacities based on the submitted bid prices. Hence, in the FBA auction the welfare of the society (i.e., the utilization of the whole network) is maximized, despite the cases of bilateral contracts and OTC markets where the allocation could be at most Pareto optimal.

Based on the notations in the Nomenclature the model is the following. The social welfare will be maximized:

$$
\max \sum_{x, y \in \text { Zones }, b \in \text { Bids }} p_{b}(x, y, b) \cdot d_{a}(x, y, b)
$$

subject to the following constraints.

The network constraints represent the PTDF and AMF structures:

$$
\begin{aligned}
& \sum_{x, y \in \text { Zones }}\left(\max (0, \operatorname{PTDF}(x, y, k)) \sum_{b \in \text { Bids }} d_{a}(x, y, b)\right) \\
\leq & A M F^{+}(k), k \in \text { Lines }, \\
& \sum_{x, y \in \text { Zones }}\left(\max (0,-\operatorname{PTDF}(x, y, k)) \sum_{b \in \text { Bids }} d_{a}(x, y, b)\right) \\
\leq & \operatorname{AMF}^{-}(k), k \in \text { Lines. }
\end{aligned}
$$

The allocated capacities cannot be negative or greater than the requested capacities:

$$
\begin{gathered}
d_{a}(x, y, b) \leq d_{b}(x, y, b), x, y \in \text { Zones }, b \in \text { Bids } \\
d_{a}(x, y, b) \geq 0, x, y \in \text { Zones }, b \in \text { Bids } .
\end{gathered}
$$

\subsection{Auction prices}

The solution of the LP problem (2.1)-(2.5) yields the allocation of capacities. However, at the end of the auction uniform auction prices have to be announced to each source-sink zone pair, too. Those can be found in the following way.

The optimal solution of the LP problem also yields Shadow Prices (dual solutions) corresponding to the constraints. E.g.,

$$
S P\left(A M F^{+}(k)\right), \operatorname{SP}\left(A M F^{-}(k)\right), k \in \text { Lines, }
$$

denote the shadow prices of lines. They represent an increase in the value of the objective function connected to the marginal increase of the corresponding $A M F$. Intuitively: the worth of one unit of capacity of the given direction of the line, regarding the optimal allocation.

The Auction Price of source-sink pair from zone $x$ to zone $y$ is given by the formula:

$$
\begin{aligned}
A P(x, y) & =\sum_{k \in \text { Lines }}\left[\max (0, \operatorname{PTDF}(x, y, k)) \cdot S P\left(A M F^{+}(k)\right)\right] \\
& +\sum_{k \in \text { Lines }}\left[\max (0,-P T D F(x, y, k)) \cdot S P\left(A M F^{-}(k)\right)\right] .
\end{aligned}
$$

Intuitively, this means that the auction price is the worth of one unit capacity on the certain source-sink pair: i.e. the sum of the usage percentage of each (directed) line multiplied by the worth of the line.

Then, the capacity allocation based on Auction Prices is the following:

- if the bid price is greater than the auction price, then the whole requested quantity of the capacity is allocated,

- if the bid price is less than the auction price, then zero capacity is allocated,

- if the bid price equals the auction price, then the requested capacity is partially satisfied until the limits of the network constraints.

From the Complementary Slackness Theorem follows that an optimal allocation of the LP problem satisfies the above rules and vice versa.

\subsection{The Market Spread Auction}

The main reason of cross-border transmission is that the price of electricity is cheaper on the market of the source zone than on the market of the sink zone. Assume that the auction participants have some forecast on the zone prices. Let us use 
Tab. 1. Characterization of the network.

\begin{tabular}{|c|c|c|c|c|c|c|c|c|}
\hline \multicolumn{5}{|c|}{ Technical Parameters for Test } & \multirow[b]{3}{*}{ AMF+ } & \multirow[b]{3}{*}{ AMF- } & \multirow[b]{3}{*}{ MAVIR $\rightarrow$ PSEO } & \multirow[b]{3}{*}{ MAVIR $\rightarrow$ ELES } \\
\hline \multicolumn{5}{|c|}{ Parameters (1008) } & & & & \\
\hline Critical Branch & Case & Source & Sink & TMF & & & & \\
\hline LINE_00001 & $n-0$ & APG & APG & 305 & 30 & 166 & 0.5 & 0.6 \\
\hline LINE_00001 & n-1 LINE_00002 & APG & APG & 305 & 20 & 126.9 & 0.1 & 0.2 \\
\hline
\end{tabular}

Tab. 2. Example for Phenomena a.

\begin{tabular}{|c|c|c|c|c|c|c|}
\hline \multicolumn{5}{|c|}{ Requested Bids } & \multicolumn{2}{|c|}{ Awarded Bids } \\
\hline Product & Source & Sink & Requested Capacity [MW] & Bid Price [EUR/MWh] & Awarded Capacity [MW] & Auction Price [EUR/MWh] \\
\hline $\mathrm{H} 01$ & MAVIR & PSEO & 70 & 1 & $0<=x<=60$ & 1 \\
\hline $\mathrm{H} 01$ & MAVIR & PSEO & 60 & 1 & $60-x$ & 1 \\
\hline
\end{tabular}

Tab. 3. Example for Phenomena b.

\begin{tabular}{ccccccc}
\hline & \multicolumn{2}{c}{ Requested Bids } & \multicolumn{2}{c}{ Awarded Bids } \\
\hline Product & Source & Sink & Requested Capacity [MW] & Bid Price [EUR/MWh] & Awarded Capacity [MW] & Auction Price [EUR/MWh] \\
\hline H01 & MAVIR & PSEO & 20 & 1 & 20 \\
H01 & MAVIR & PSEO & 10 & 0 & $0<=x<=10$ \\
\hline
\end{tabular}

Tab. 4. Example for Phenomena c.

\begin{tabular}{|c|c|c|c|c|c|c|}
\hline \multicolumn{5}{|c|}{ Requested Bids } & \multicolumn{2}{|c|}{ Awarded Bids } \\
\hline Product & Source & Sink & Requested Capacity [MW] & Bid Price [EUR/MWh] & Awarded Capacity [MW] & Auction Price [EUR/MWh] \\
\hline $\mathrm{H} 01$ & MAVIR & PSEO & 20 & 10 & 20 & 5 \\
\hline $\mathrm{H} 01$ & MAVIR & ELES & 20 & 12 & 20 & 6 \\
\hline $\mathrm{H} 01$ & MAVIR & PSEO & 20 & 5 & $0<=x<=16$ & 5 \\
\hline $\mathrm{H} 01$ & MAVIR & ELES & 20 & 6 & $80 / 6-5 / 6^{*} x$ & 6 \\
\hline
\end{tabular}

the following notations:

$$
p_{\text {bid }}(x), p_{\text {ask }}(x)
$$

are the bid and ask price of one unit electricity at Zone $x$. Then assume that all bid prices are their reasonable upper limit. The question is that how much capacity is allocated on each sinksource pair. I.e., the following auction is considered: one bid for each source-sink pair is submitted with parameters

$$
\begin{gathered}
p_{b}(x, y, b)=p_{b i d}(y)-p_{a s k}(x), d_{b}(x, y, b)=+\infty, \\
\text { for all } x, y \in \text { Zones. }
\end{gathered}
$$

In practice, the market spread auction is the most common tool to get a first impression on the market before bidding. However, the forecasts of the zone prices have errors. Hence, the sensitivity analysis, which is presented in the following section, is very important.

\section{Multiple optima, sensitivity analysis \\ 3.1 Multiple optima}

The auction rule is well-defined only if it yields unique allocation and auction prices for each bid combination. As regards the allocation the multiple optima of the primal LP problem can be problematic, while the multiple optima of the dual problem can cause indeterminate auction prices. As it will be seen, the primal case is regulated well by the auction rules while in the dual case the multiple optima do not occur in practice.

\subsection{Alternative optimal allocations}

The following phenomena can happen:

(a) there are two bids with same Source-Sink Pair and Bid Price and at least one of their requests is just partially satisfied,

(b) there is a bid with zero bid price which can be (at least partially) satisfied,

(c) there are other types of multiple optimal solutions.

Let us consider some examples illustrating the above phenomena. The network is characterized in Table 1.

Table 1 follows the structure of the CAO datasheet (see Figure 1) and it is assumed to be valid for the first hour of the day (H01). In the following, only bids on the MAVIR->PSEO and MAVIR->ELES are considered. Hence only data in bold are important for us.

The examples follow the structure of CAO result sheet. The product 'H01' means that the bids submitted for the first hour of the day. Phenomena a, b, c are illustrated in Tables 2, 3, 4, respectively. 
Tab. 5. Characterization of the network of Example 3.1.

\begin{tabular}{|c|c|c|c|c|c|c|c|}
\hline \multicolumn{5}{|c|}{ Technical Parameters for Test } & \multirow[b]{3}{*}{ AMF+ } & \multirow[b]{3}{*}{ AMF- } & \multirow[b]{3}{*}{ MAVIR $\rightarrow$ PSEO } \\
\hline \multicolumn{5}{|c|}{ Parameters (1008) } & & & \\
\hline Critical Branch & Case & Source & Sink & TMF & & & \\
\hline LINE_00001 & $n-0$ & APG & APG & 305,2 & 30 & 166 & 0.5 \\
\hline
\end{tabular}

Tab. 6. Submitted bid and results of Example 3.1.

\begin{tabular}{ccccccccccc}
\hline \multicolumn{4}{c}{ Requested Bids } & & & Awarded Bids \\
\hline Product & Source & Sink & $\begin{array}{c}\text { Requested } \\
\text { Capacity [MW] }\end{array}$ & $\begin{array}{c}\text { Bid Price } \\
{[\text { EUR/MWh] }}\end{array}$ & Product & Source & $\begin{array}{c}\text { Sink } \\
\text { Awarded } \\
\text { Capacity [MW] }\end{array}$ & $\begin{array}{c}\text { Auction Price } \\
{[\text { EUR/MWh] }}\end{array}$ \\
\hline H01 & MAVIR & PSEO & 60 & 1 & H01 (1h) & MAVIR & PSEO & 60 & $0<=x<=10$ \\
\hline
\end{tabular}

The first two situations are managed by Annex 5 of the Auction Rules of CAO (2011):

- As regards Situation a: The "First-Come-First-Serve Principle." has to be used. I.e., the bid submitted earlier must be preferred.

- Regarding Situation b: the auction rules say "the Bid Price is replaced for optimization algorithm purposes with a very small number not influencing the Auction Price calculation.”. I.e., if any unused capacity remains in the network, it must be allocated among the submitted zero-priced bids.

Multiple optimal allocations can be arisen only in case of multiple optimal (primal) bases. Hence, alternative allocations can be produced only by the precise setting of the bid prices and/or the PTDF and AMF values. This situation can happen naturally only in case of Phenomena a and b. The problems with Phenomenon c cannot arise spontaneously thanks to the number of rows and the structure of the PTDF matrix. However, those problems can be set artificially, see e.g. Figure 3. Hence, in practice the Auction Rules exclude the undefined allocations. This was confirmed by the results of CAO FBA Dry Run II (2009).

\subsection{Alternative auction prices}

As regards the auction prices, they can be indefinite in case of multiple optima of the dual of the (auction) LP problem. Beside complex situations, this can arise as in the following simple example.

Example 3.1 The PTDF matrix is defined in Table 5. The submitted bid and results are illustrated in Table 6. The reason of multiple dual optima is that in the LP model the (AMF+) constraint (2.2) of LINE_00001 and the (requested capacity) constraint (2.4) of the bid are fulfilled by equality at the same time. This means that the values of the corresponding (primal) slack variables are zero. Those variables represent the optimality conditions of the dual problem, hence, the only dual basis variable can correspond to the constraint of LINE_00001 or to the bid constraint. This means two optimal dual basesand infinite optimal dual solutions. Indeed, if we perturb the requested capacities:

- in case of e.g., 59MW requested capacity, exactly the bid constraint will be the basis and the auction price will be zero (the awarded capacity will be 59),
- in case of e.g., 61MW requested capacity, exactly the $A M F+$ constraint will be the basis and the auction price will be 10 (the awarded capacity will be 60).

The Auction Rules do not exclude the multiple dual solutions. However, among the practical tests of CAO FBA Dry Run II (2009) there is no example for alternative auction prices.

\subsection{Sensitivity analysis of Market Spread Auction}

In this section the Market Spread Auction, defined in Section 2.3, is considered. Assume that the bid and ask prices of electricity at a given Zone $k$ change by the same value $\Delta p$. Let the changed solution be marked by “ ، ". The questions are

(a) the sensitivities of Auction Prices. i.e.

$\frac{\Delta A P(x, y)}{\Delta p}=\frac{A P^{\prime}(x, y)-A P(x, y)}{\Delta p}$, for all $x, y \in$ Zones, $x \neq y$.

(b) The sensitivity intervals. I.e., the intervals, where

$$
\frac{\Delta A P(x, y)}{\Delta p}
$$

as well as the accepted capacities

$$
d_{a}^{\prime}(x, y, b)
$$

for all $\mathrm{x}, \mathrm{y} \in$ Zones, $x \neq y$ remain constant.

Let us illustrate the above by the following

Example 3.2 Consider a Market Spread Auction with PTDF matrix "Test 2 Daily Auction 7AB" in CAO FBA Dry Run II (2009) and Zone prices

$$
\begin{gathered}
p_{\text {bid }}\left(C Z \_S K\right)=p_{\text {ask }}\left(C Z \_S K\right)=43 ; \\
p_{\text {bid }}(P S E O)=p_{\text {ask }}(P S E O)=43 ; \\
p_{\text {bid }}(M A V I R)=p_{\text {ask }}(M A V I R)=54 ; \\
p_{\text {bid }}(E L E S)=p_{\text {ask }}(E L E S)=34 .
\end{gathered}
$$

Assume that

$$
p_{b i d}\left(D E \_A T\right)=p_{\text {ask }}\left(D E \_A T\right) .
$$

The Auction Prices depending on the price of Zone DE_AT are presented on Figure 2. The Awarded Capacities depending on the price of Zone DE_AT are depicted by Figure 3. It is 


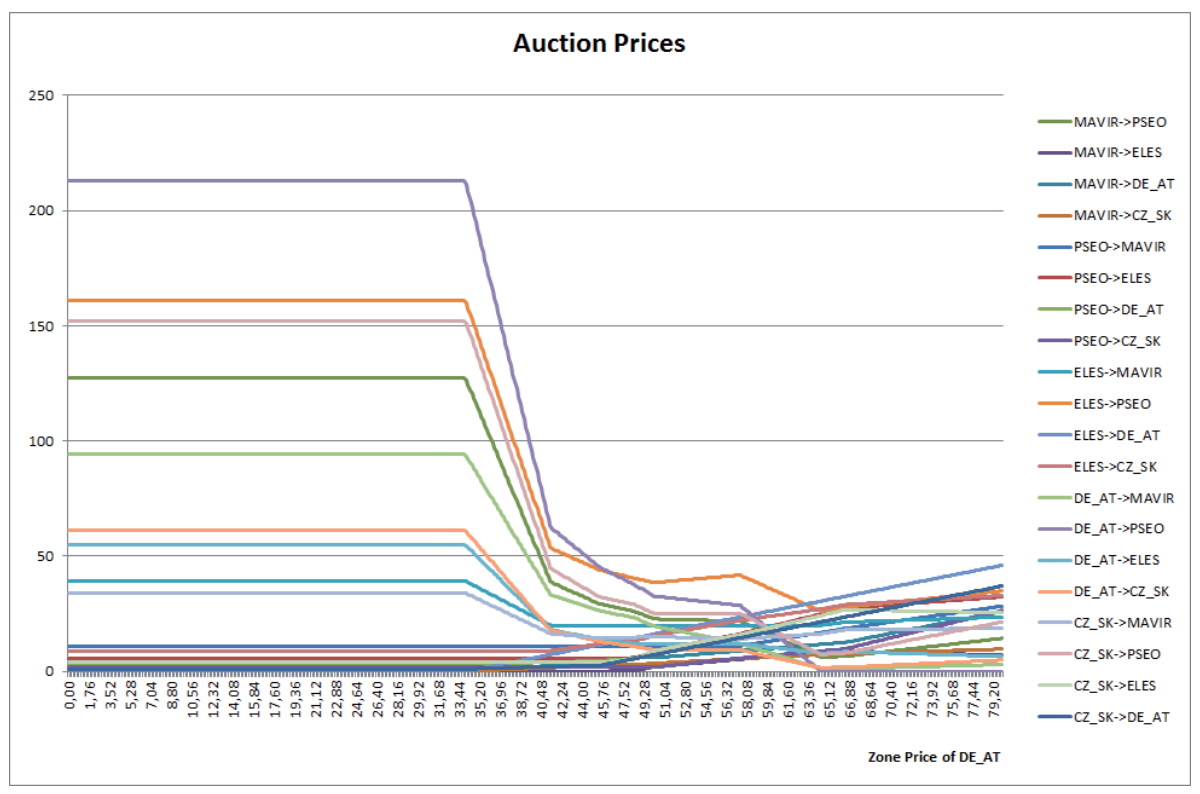

Fig. 2. Auction Prices depending on the price of Zone DE_AT

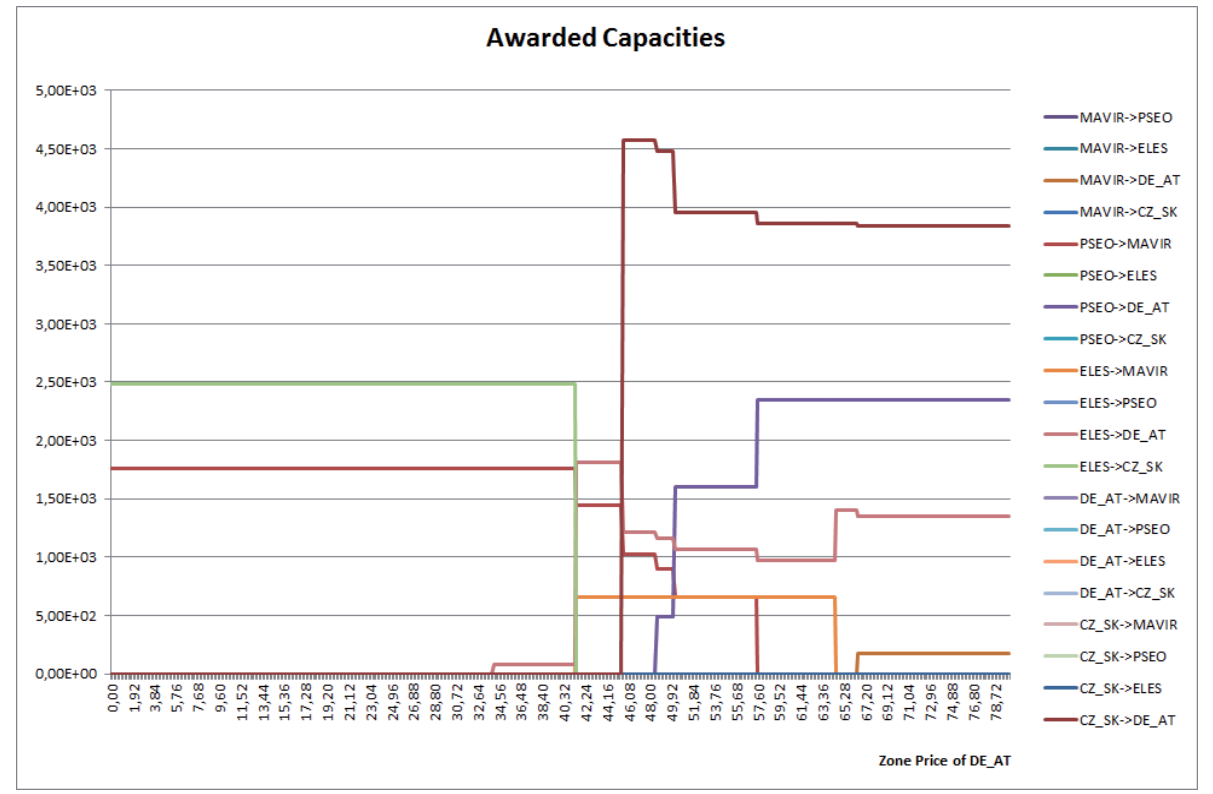

Fig. 3. Awarded Capacities depending on the price of Zone DE_AT

easy to see that both types of sensitivity are constant on certain intervals. The endpoints of those intervals correspond to the changes of optimal bases of the LP problem. This can be illustrated by the mixed chart of Figure 4, where the intervals are changing at the same points.

In order to calculate the endpoints of the sensitivity intervals a special sensitivity analysis should be applied because more than one parameter of the LP is changing. I.e., if the price of Zone $k$ changes by $\Delta p$, then the new bid prices will be

$$
\begin{gathered}
p^{\prime}(k, y, b)=p_{b i d}(y)-\left(p_{a s k}(k)+\Delta p\right)=p(k, y, b)-\Delta p, \\
p^{\prime}(x, k, b)=\left(p_{b i d}(k)+\Delta p\right)-p_{a s k}(x)=p(k, y, b)+\Delta p, \\
p^{\prime}(x, y, b)=p_{b i d}(y)-p_{a s k}(x)=p(x, y, b),
\end{gathered}
$$

where $x \neq y, x \neq k, y \neq k$.
Let us use the compact form of Market Spread Auction problem:

$$
\boldsymbol{p}^{T} \boldsymbol{d} \rightarrow \max
$$

subject to

$$
\begin{aligned}
A \boldsymbol{d} & \leq \boldsymbol{b} \\
\boldsymbol{d} & \leq \mathbf{0},
\end{aligned}
$$

where constraints (3.6) are the network constraints (2.2), (2.3) of the auction LP problem. The bid constraints (2.4) are skipped, because the values of the requested capacities are infinity.

Let $\mathrm{B}$ be the matrix of optimal basis of the above problem.

The vector of changed bid prices can be written into the form:

$$
p^{\prime}=p+\Delta p \cdot u
$$

where

$u(k, y, b)=-1, u(x, k, b)=+1, u(x, y, b)=0, x \neq y, x \neq k, y \neq k$. 


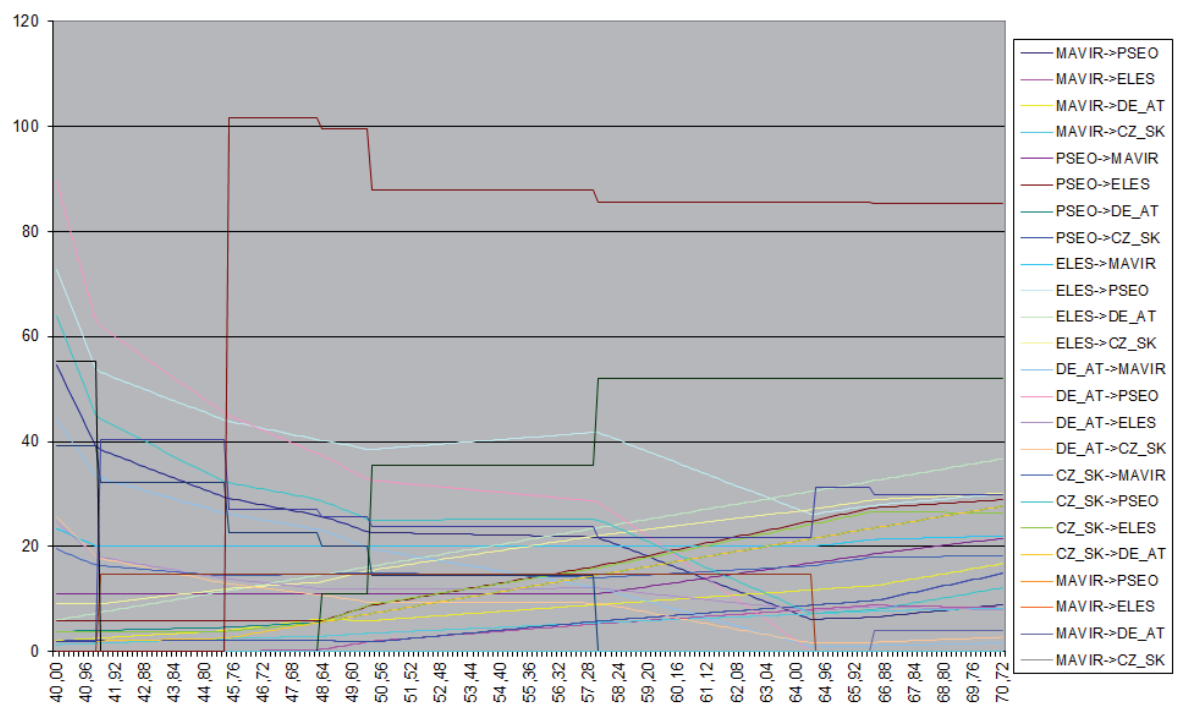

Fig. 4. Endpoints of sensitivity intervals are at the changes of optimal bases

Tab. 7. Characterization of the network.

\begin{tabular}{|c|c|c|c|c|c|c|c|c|}
\hline \multicolumn{5}{|c|}{ Technical Parameters for Test } & \multirow[b]{3}{*}{ AMF+ } & \multirow[b]{3}{*}{ AMF- } & \multirow[b]{3}{*}{ MAVIR $\rightarrow$ PSEO } & \multirow[b]{3}{*}{ MAVIR $\rightarrow$ ELES } \\
\hline \multicolumn{5}{|c|}{ Parameters (1008) } & & & & \\
\hline Critical Branch & Case & Source & Sink & TMF & & & & \\
\hline LINE_00001 & $n-0$ & APG & APG & 305 & 30 & 166 & 1 & 0 \\
\hline LINE 00001 & n-1 LINE 00002 & APG & APG & 305 & 20 & 126.9 & 1 & 1 \\
\hline
\end{tabular}

Then the optimality conditions of $B$ :

$$
p_{B}^{\prime}{ }^{T} B^{-1} A-p^{T} \geq 0 \text { and } p_{B}{ }^{T} B^{-1} \geq 0 T
$$

Substituting (3.7) the above inequalities can be written as

$$
\underbrace{\left(p_{B}^{T} B^{-1} A-p^{T}\right)}_{w_{\text {opt }} T_{\geq 0} T}+\Delta p \cdot \underbrace{\left(u_{B}^{T} B^{-1} A-u^{T}\right)}_{w_{u}^{T}} \geq 0^{T}
$$

and

$$
\underbrace{\left(p_{B}^{T} B^{-1}\right)}_{y_{o p t} T_{\geq 0}^{T}}+\Delta p \cdot \underbrace{\left(u_{B}^{T} B^{-1}\right)}_{y_{u}^{T}} \geq 0
$$

Hence, the sensitivity interval is $\Delta p \in\left(\Delta p_{\min }, \Delta p_{\max }\right)$ where

$$
\Delta p_{\min }=-\min \left(\min _{i \in I} \frac{w_{o p t}^{(i)}}{\max \left(0, w_{u}^{(i)}\right)}, \min _{j \in J} \frac{y_{o p t}^{(j)}}{\max \left(0, y_{u}^{(j)}\right)}\right)
$$

and

$$
\begin{gathered}
\Delta p_{\max }=\min \left(\min _{i \in I} \frac{w_{o p t}^{(i)}}{\max \left(0,-w_{u}^{(i)}\right)}, \min _{j \in J} \frac{y_{\text {opt }}^{(j)}}{\max \left(0,-y_{u}^{(j)}\right)}\right), \\
|I|=\mid \text { Zones } \mid \cdot(\mid \text { Zones } \mid-1),|J|=2 \cdot \mid \text { Lines } \mid .
\end{gathered}
$$

Remark, in case of simultaneous changes of the Zone prices the sensitivity analysis can be solved similarly. The difference is that instead of intervals, the sensitivity remains constant if $\Delta p$ is within a certain polyhedron.

\section{Social welfare and total revenue of the TSOs}

In the CAO auction rules the objective function of the LP problem is calculated by the submitted bid prices while the bidders have to pay only the uniform auction prices of the sourcesink pairs. I.e., the objective is to maximize

$$
F=\sum_{x, y \in \text { Zones }, b \in \text { Bids }} p_{b}(x, y, b) \cdot d_{a}(x, y, b),
$$

however, the real revenue of CAO (TSOs) is

$$
R=\sum_{x, y \in \text { Zones }, b \in \text { Bids }} A P(x, y) \cdot d_{a}(x, y, b) .
$$

Hence, the income of the TSOs will be usually different to the value of the objective function. In order to illustrate the arising questions consider the PTDF and AMF values of Table 7.

Example 4.1 Consider the bids and results of Table 8.

Here, the optimal value of the objective function is:

$$
F=10 \cdot 19+1 \cdot 1=191,
$$

however, the corresponding income is only

$$
R=1 \cdot 19+1 \cdot 1=20 \text {. }
$$

In this section an alternative auction model is presented where

- uniform prices are announced, 
Tab. 8. Submitted bid and results of Example 4.1.

\begin{tabular}{ccccccccc}
\hline Product & Source & Sink & $\begin{array}{c}\text { Requested } \\
\text { Capacity [MW] }\end{array}$ & $\begin{array}{c}\text { Bid Price } \\
\text { [EUR/MWh] }\end{array}$ & Source & Sink & $\begin{array}{c}\text { Awarded } \\
\text { Capacity [MW] }\end{array}$ & $\begin{array}{c}\text { Auction Price } \\
\text { [EUR/MWh] }\end{array}$ \\
\hline H01 & MAVIR & PSEO & 19 & 10 & MAVIR & PSEO & 19 & 1 \\
\hline H01 & MAVIR & PSEO & 2 & 1 & MAVIR & PSEO & 1 & 1 \\
\hline
\end{tabular}

Tab. 9. Submitted bid and results of Example 4.2.

\begin{tabular}{|c|c|c|c|c|c|c|c|c|}
\hline Product & Source & Sink & $\begin{array}{c}\text { Requested } \\
\text { Capacity [MW] }\end{array}$ & $\begin{array}{c}\text { Bid Price } \\
\text { [EUR/MWh] }\end{array}$ & $\begin{array}{c}\text { Awarded } \\
\text { Capacity [MW] }\end{array}$ & $\begin{array}{c}\text { Auction Price } \\
\text { [EUR/MWh] }\end{array}$ & $\begin{array}{c}\text { Awarded } \\
\text { Capacity }[\mathrm{MW}]\end{array}$ & $\begin{array}{c}\text { Auction Price } \\
\text { [EUR/MWh] }\end{array}$ \\
\hline H01 & MAVIR & PSEO & 19 & 10 & 19 & 1 & 19 & 10 \\
\hline $\mathrm{H} 01$ & MAVIR & PSEO & 2 & 1 & 1 & 1 & 0 & 10 \\
\hline \multirow[t]{2}{*}{ H01 } & MAVIR & ELES & 1 & 0 & 0 & 0 & 1 & 0 \\
\hline & & & & & Revenue & 20 & Revenue & 190 \\
\hline
\end{tabular}

- the rules of "capacity allocation based on Auction Prices" of Section 2.2 remain valid,

- the objective function is the total income and

- in the capacity allocation there are no residual capacities that can be allocated among the remaining capacity requests. (The model efficiently deals with interdependent physical flows.)

Hence, the auction model fulfills the requirements of the European Community Regulations (see Section 1). Comparing this model to the model of CAO:

- the objective function of the alternative model is more reasonable.

- Despite the LP problem of CAO, the alternative model is a nonconvex nonlinear programming problem.

Let us illustrate the difference between the two models by the following example

Example 4.2 Consider the PTDF matrix of Table 7 and the bids and results of Table 9. The $6^{\text {th }}$ and $7^{\text {th }}$ columns show the results of auction LP of CAO while the last two columns represent the solution of the alternative model with income maximization.

The exact formulation of the alternative model is the following. The notions are the same as at the LP problem of Section 2.1 completed by the following type of variables:

$d_{r}(x, y, b)$ :

the remaining demand that can be satisfied from the residual capacities at the end of the auction.

Those variables must equal zero in order to allocate the capacities efficiently.

Hence, the objective function is

$$
\max \sum_{x, y \in \text { Zones }, b \in \text { Bids }}\left(A P(x, y) \cdot d_{a}(x, y, b)-M \cdot d_{r}(x, y, b)\right)
$$

where $M$ is a big number.

The following constraints are considered. No allocated capacity under the auction price:

$$
\begin{aligned}
& d_{a}(x, y, b)\left(A P(x, y)-p_{b}(x, y, b)\right) \\
& \leq 0 x, y \in \text { Zones }, b \in \text { Bids }
\end{aligned}
$$

All requested capacities above the auction price are fully satisfied:

$$
\begin{aligned}
& \left(d_{b}(x, y, b)-d_{a}(x, y, b)\right)\left(p_{b}(x, y, b)-A P(x, y)\right) \\
& \leq 0 \quad x, y \in \text { Zones, } b \in \text { Bids }
\end{aligned}
$$

The allocated and free capacities:

$$
\begin{aligned}
& \sum_{x, y \in \text { Zones }}\left(\max (0, \operatorname{PTDF}(x, y, k)) \sum_{b \in \text { Bids }}\left(d_{a}(x, y, b)+d_{r}(x, y, b)\right)\right) \\
& \leq A M F^{+}(k), \\
& \sum_{x, y \in \text { Zones }}\left(\max (0,-\operatorname{PTDF}(x, y, k)) \sum_{b \in \text { Bids }}\left(d_{a}(x, y, b)+d_{r}(x, y, b)\right)\right) \\
& \leq A M F^{-}(k),
\end{aligned}
$$

$$
k \in \text { Lines, }
$$

Constraints corresponding to the bid properties:

$$
\begin{aligned}
& d_{a}(x, y, b)+d_{r}(x, y, b) \leq d_{b}(x, y, b), \\
& x, y \in \text { Zones, } b \in \text { Bids }
\end{aligned}
$$

The (nonnegative) variables are:

$$
\begin{gathered}
d_{a}(x, y, b) \geq 0 \quad x, y \in \text { Zones }, b \in \text { Bids } \\
d_{r}(x, y, b) \geq 0 \quad x, y \in \text { Zones }, b \in \text { Bids } \\
A P(x, y) \geq 0 x, y \in \text { Zones } .
\end{gathered}
$$

The nonnegativities of the remaining demands with constraints (4.12) prevent against the overloading.

Problem (4.9) - (4.16) is a nonconvex (quadratically constrained) quadratic programming problem (QP). This type of problems can be solved, e.g., by the method of Audet et al. (2000). However, possibly a more effective solution method could be found by the exploitation of the special properties of the problem. It is based on the simple fact, that the maximum is attained at auction prices that equal to one of the submitted bid prices. The detailed development of the method is out of the scope of this paper and will be the part of future research. 
Tab. 10. Auction prices based on shadow prices vs. based on bid prices with the same capacity allocation

\begin{tabular}{|c|c|c|c|c|c|c|}
\hline \multicolumn{6}{|c|}{ Aggregated Auction Results } & \multirow[b]{2}{*}{$\begin{array}{c}\text { Auction Price } \\
\text { (independent from } \\
\text { shadow prices) } \\
\text { [EUR/MWh] }\end{array}$} \\
\hline Product & Source & Sink & $\begin{array}{l}\text { Requested Capacity } \\
\qquad[\mathrm{MW}]\end{array}$ & $\begin{array}{c}\text { Awarded Capacity } \\
{[\mathrm{MW}]}\end{array}$ & $\begin{array}{c}\text { Auction Price } \\
\text { (based on shadow } \\
\text { prices) } \\
\text { [EUR/MWh] }\end{array}$ & \\
\hline $\mathrm{H} 10$ & APG & CEPS & 101 & 0 & 111.45 & 1 \\
\hline $\mathrm{H} 10$ & APG & ELES & 90 & 0 & 200 & 51 \\
\hline $\mathrm{H} 10$ & APG & MAVIR & 156 & 0 & 142.32 & 50 \\
\hline $\mathrm{H} 10$ & CEPS & APG & 99 & 99 & 0 & 0 \\
\hline $\mathrm{H} 10$ & CEPS & ELES & 240 & 200 & 103.06 & 200 \\
\hline $\mathrm{H} 10$ & CEPS & MAVIR & 70 & 10 & 32.53 & 50 \\
\hline $\mathrm{H} 10$ & CEPS & TPS & 135 & 135 & 0 & 0 \\
\hline $\mathrm{H} 10$ & CEPS & VET & 135 & 135 & 0 & 0 \\
\hline $\mathrm{H} 10$ & ELES & APG & 87 & 87 & 0 & 0.5 \\
\hline $\mathrm{H} 10$ & ELES & CEPS & 200 & 200 & 14.25 & 200 \\
\hline $\mathrm{H} 10$ & ELES & MAVIR & 270 & 200 & 47.05 & 200 \\
\hline $\mathrm{H} 10$ & ELES & PSEO & 200 & 0 & 220.45 & 201 \\
\hline $\mathrm{H} 10$ & ELES & TPS & 200 & 200 & 0 & 200 \\
\hline $\mathrm{H} 10$ & ELES & VET & 200 & 200 & 0 & 200 \\
\hline $\mathrm{H} 10$ & MAVIR & APG & 105 & 105 & 0 & 0 \\
\hline $\mathrm{H} 10$ & MAVIR & ELES & 250 & 200 & 104.73 & 200 \\
\hline $\mathrm{H} 10$ & MAVIR & PSEO & 100 & 58 & 200 & 200 \\
\hline $\mathrm{H} 10$ & MAVIR & SEPS & 180 & 50 & 1.66 & 3 \\
\hline $\mathrm{H} 10$ & PSEO & ELES & 200 & 200 & 78.96 & 200 \\
\hline $\mathrm{H} 10$ & PSEO & SEPS & 10 & 10 & 0 & 0.14 \\
\hline $\mathrm{H} 10$ & PSEO & VET & 35 & 35 & 0 & 30 \\
\hline $\mathrm{H} 10$ & SEPS & ELES & 20 & 0 & 103.06 & 51 \\
\hline $\mathrm{H} 10$ & SEPS & MAVIR & 80 & 10 & 32.53 & 50 \\
\hline $\mathrm{H} 10$ & TPS & CEPS & 315 & 0 & 111.45 & 2 \\
\hline $\mathrm{H} 10$ & TPS & ELES & 200 & 0 & 200 & 200 \\
\hline $\mathrm{H} 10$ & VET & CEPS & 115 & 0 & 111.45 & 1 \\
\hline \multirow[t]{2}{*}{$\mathrm{H} 10$} & VET & ELES & 200 & 0 & 200 & 200 \\
\hline & & & & Real Income: & 81943.6 & 293844.9 \\
\hline
\end{tabular}

Here, only one illustrative practical example is presented in order to show, that based on the capacity allocation of the original linear programming auction method, higher income can be realized by setting the auction prices independently from the shadowprices of the lines.

Example 4.3 Consider Hour 10 in Test Daily 2 Auction $7 A$ of CAO FBA Dry Run II (2009). Table 10 shows the auction prices of the LP method and auction prices resulting the same allocation based on the rules of Section 2.2. In the second case simply the highest bid prices have been chosen, which do not change the allocation (i.e., the bid prices at the border between the zero and positive allocations). The values of the real total incomes are also presented.

Remark that the total income may be increased further by finding the optimal capacity allocations of the new model. However, in order to do this a special nonconvex QP solver is needed.
Example 4.3 presents a practical test problem where still in case of the same capacity allocation, the use of auction prices independent from the shadow prices can result higher income.

Remark that one reason for the use of auction prices based on shadow prices is that shadow prices play an important role in some possible distribution methods of the income, see Leuthod and Todem (2007). However, the shadow prices are calculated on the base of the submitted prices, and does not reflect the auction prices.

The above experiences have exploited some important properties and drawbacks of the auction method. They can help in thinking over the auction rules as well as in development of bidding strategies.

\section{Conclusion}

The paper presents an introduction to the mathematical part of the FBA auction rules with a more detailed discussion than 
the rules of CAO (2011). This, completed with the examples and numerical experiences, can make the paper a useful guide to learn about the FBA auction mechanism.

From the mathematical point of view, on one hand, the description of sensitivity analysis of zone prices can help in its implementation to programmers and/or business analysts.

\section{Nomenclature}

\section{Abbreviations}

50HzT 50Hertz Transmission GmbH, German TSO.

$\mathrm{AMF}+$

(AMF-) Available Maximum Flow in the (opposite) direction of the line.

APG APG-Austrian Power Grid AG., Austrian TSO.

$\mathrm{CAO}$ Central Allocation Office.

CEE Central-Eastern Europe Region.

CEPS ČEPS, a.s., Czech TSO.

CZ SK Zone of CEPS and SEPS.

DE_AT Zone of 50HzT, APG and TENNET.

ELES Elektro-Slovenija, d.o.o., Slovenian TSO and its zone.

ETSO-E European Network of Transmission System Operators for Electricity.

FBA Flow-based Capacity Allocation.

MAVIR Hungarian Transmission System Operator Company Ltd., Hungarian TSO and its zone.

NTC Net Transfer Capacity.

OTC Over-the-counter or off-exchange trading.

PSEO PSE Operator S.A., Polish TSO and its zone.

PTDF Power Transfer Distribution Factor.

SEPS Slovenská elektrizačná prenosová sústava, a.s., Slovak TSO.

TENNET TenneT TSO GmbH, German TSO.

TMF Total Maximum Flow. The technical upper limit on the power flow on the network element.

TSO
On the other hand, the formalization of the revenue maximization problem, beside its illustrative role, can be the first step to develop better bidding strategies.

Remark that all methods and experiences of the paper can be applied to the present NTC allocation mechanism described in Annex 6 of the rules of CAO (2011), as well.

\section{Indices}

Bids Set of indices of offered bids.

$k \quad$ Line index.

Lines Set of indices of the critical lines.

$x \quad$ Source zone index.

$y \quad$ Sink zone index.

Zones Set of indices of zones.

\section{Parameters}

$A M F^{+}(k) \quad$ Maximum capacity in the direction of $k$.

$A M F^{-}(k) \quad$ Maximum capacity in the opposite direction of $k$.

$d_{a}(x, y, b) \quad$ Allocated quantity for bid $b$.

$d_{b}(x, y, b) \quad$ Requested capacity for bid $b$.

$p_{a s k}(x) \quad$ Ask price of one unit electricity at Zone $x$.

$p_{b}(x, y, b) \quad$ Bid price of bid $b$ (on the source-sink $x \rightarrow y$ ).

$p_{b i d}(x) \quad$ Bid price of one unit electricity at Zone $x$. $\operatorname{PTDF}(x, y, k)$

Value of capacity that used on $k$ in case of transmission of $1 M W$ from $x$ to $y$.

\section{Variables}

$A P(x, y) \quad$ Auction Price of source-sink pair from zone $x$ to zone $y$.

$d(x, y, b) \quad$ Allocated quantity for bid $b$

$\operatorname{SP}\left(A M F^{+}(k)\right)$ Shadow price of the direction of line $k$.

$S P\left(A M F^{-}(k)\right) \quad$ Shadow price of the opposite direction of line $k$.

\section{Acknowledgements}

The authors would like to thank Balázs Bánhelyi at University of Szeged for his valuable comments on the properties of the global optimization problem.

\section{References}

Audet C., Hansen P., Jaumard B., Savard G. (2000) A branch and cut algorithm for nonconvex quadratically constrained quadratic programming. Mathematical Programming. 87 (1), pp. 131-152. DOI: $10.1007 / \mathrm{s} 101079900106$

Boucher J., Smeers Y. (2002) Towards a common European electricity market - paths in the right direction ... still far from an effective design. Journal of Network Industries. 3, pp. 375-424.

\section{CAO FBA Dry Run II.}

ZIP file: http://www.math.bme.hu/ gnagy/CAO/CAODryRun2.zip. Original Source: http://www.central-ao.com/project/dry-runs (2009).

CAO ePortal (2011) Home. [Online] Available from: http://www.centralao.com. [Accessed: 10th May 2014] 
CAO (2011) Rules for Coordinated Auction of Transmission Capacity in the CEE-Region. [Online] Available from: http://www.50hertz.com/en/file/ auction_rules_28_11_2011_binding.pdf. [Accessed: 10th May 2014]

Ding F., Fuller J. D. (2005) Nodal, uniform, or zonal pricing: distribution of economic surplus. IEEE Transactions on Power Systems, 20 (2), pp. 875-882.

DOI: $\underline{10.1109 / T P W R S .2005 .846042}$

Ehrenmann A., Smeers Y. (2005) Inefficiencies in European congestion management proposals. Utilities Policy, 13 (2), pp. 135-152. DOI: $\underline{10.1016 / j . j u p .2004 .12 .007}$

ETSO-E (2012) European Network of Transmission System Operators for Electricity. [Online] Available from: https://www.entsoe.eu. [Accessed: 10th May 2014]
Leuthold F., Todem C. (2007) Flow-Based Coordinated Explicit Auctions: Auction Income Distribution. Electricity Markets Working Papers WPEM-19.

Leuthold F., Weigt H., von Hirchhausen C. (2008) Efficient pricing for European electricity networks - The theory of nodal pricing applied to feeding-in wind in Germany. Utilities Policy, 16 (4), pp. 284-291. DOI: $10.1016 /$ j.jup.2007.12.003

Stigler H., Todem C. (2005) Optimization of the Austrian electricity sector (control zone of VERBUND APG) under the constraints of network capacities by nodal pricing. Central European Journal of Operations Research, 13, pp. 105-125. 